\title{
Rapid detection of antimicrobial residues in poultry: A consequence of non-prudent use of antimicrobials
}

\author{
Ekene Vivienne Ezenduka*, Oboegbulem Steve Ike, Nwanta John Anaelom
}

Department of Veterinary Public Health and Preventive Medicine, University of Nigeria, Nsukka, Nigeria;

*Corresponding Author: ev.ezenduka@yahoo.com

Received 19 November 2013; revised 29 December 2013; accepted 15 January 2014

Copyright (C) 2014 Ekene Vivienne Ezenduka et al. This is an open access article distributed under the Creative Commons Attribution License, which permits unrestricted use, distribution, and reproduction in any medium, provided the original work is properly cited. In accordance of the Creative Commons Attribution License all Copyrights (C) 2014 are reserved for SCIRP and the owner of the intellectual property Ekene Vivienne Ezenduka et al. All Copyright (C) 2014 are guarded by law and by SCIRP as a guardian.

\section{ABSTRACT}

A cross sectional survey was conducted in three major poultry markets at Enugu Urban area of Enugu State, South Eastern, Nigeria, to determine the prevalence of antimicrobial residues in commercial broiler birds using Premi® Test Kit. Antimicrobials generally due to their availability over the counter and non-enforcement of legislature on irrational use are often abused in both veterinary and medical practice in most developing countries. The misuse and overuse of these drugs lead to deposition of violative levels of antimicrobial residues in animal tissues meant for human consumption with several health consequences when consumed. Premi ${ }^{\circledR}$ Test like all other microbiological tests is based on the principle of inhibition and was able to detect antibiotic residues in $42(60 \%)$ of the 70 sampled commercial birds from three major poultry markets in the study area. It detected also residues in $\mathbf{9 0}$ out of the $\mathbf{2 8 0}$ different organ matrices made up of 70 samples of each organ, of which Kidney was the highest at $48.6 \%$, Gizzard $(30.1 \%)$, liver (25.8\%), and muscle $(24.3 \%)$ in that order. No association was found between the occurrence of antibiotic residues and the location of the poultry markets sampled at $P<$ 0.05 while a strong association between antibiotic residues and the organ type at $P<0.05$ was found.

\section{KEYWORDS}

Antimicrobial Residues; Premi ${ }^{\circledR}$ Test; Commercial; Poultry; Nigeria

\section{INTRODUCTION}

Poultry industry is one of the fastest means of ameliorating the animal protein deficiency in Nigeria. The high turn-over rate and the quest for white meat have given more credence to poultry among livestock farming. The need to meet up with the demand for poultry meat has necessitated the large scale production of poultry and subsequent use of veterinary drugs, especially antimicrobials. These antimicrobials are particularly used in poultry farming for therapeutic purposes and are added in feed and water in sub-therapeutic doses for prophylaxis and growth promotion [1]. They tend to accumulate in tissues and organs to form residues at different concentrations. Presence of drugs or antibiotics residues in food above the maximum level is recognized worldwide by various public health authorities as being illegal [2] and their consumption could result in public health hazards including: development of resistant strains of microorganisms, hypersensitive reaction in sensitised individuals $[3,4]$ and distortion of intestinal microflora [5,6], and [7] have suggested economic losses in the food industry especially in interfering with starter culture in yoghurt and cheese production consequent upon the presence of antibiotics residues in milk. Therefore, detection of these residues in foods of animal origin intended for human consumption is essential for the safety of consumers. Detection of drug residues from tissues and other animal products could be quite an expensive, time consuming and laborious venture. Microbiological methods are quite suitable for the detection of antimicrobial residues especially as they are less expensive than immunochemical and chromatographic methods, and are able to screen a large number of samples at minimal cost [8]. Many microbiological tests have been developed for detection of antimicrobial residues and most are relatively cheap to apply. Premi ${ }^{\circledR}$ Test is a microbial screening test for the 
detection of antimicrobial residues in foods of animal origin. The test is based on the inhibition of growth of Bacillus stearothermophilus, a thermophilic bacterium sensitive to many antibiotics and sulpha compounds [9]. The Premi ${ }^{\circledR}$ Test allows to screen meat (beef, pork, poultry) for the residues of $\beta$-lactam, cephalosporins, macrolids, tetracycline, sulphonamides, aminoglycosides, quinolones, amphenocols and polypeptides. The kit has AFNOR validation for the screening of $\beta$-lactam, macrolids, tetracycline and sulphonamides in beef, pork and poultry. It has a detection limit in line with the EU Maximum Residue Limits (MRL's) and needs little time for incubation.

\section{MATERIALS AND METHOD}

\subsection{Study Area and Sample Collection}

70 commercial broiler birds were randomly selected and purchased from the three major poultry markets in Enugu urban, Enugu State, Southeast, Nigeria. 30 birds were purchased from Artisan Market which is the biggest poultry market in Enugu urban and 20 each from Gariki and Ogbete main markets. Liver, kidney, breast muscle and gizzard were harvested from each of the 70 birds after slaughter, a total of 280 samples, each organ making up a sample.

\subsection{Sample Preparation}

$5 \mathrm{~g}$ of each organ sample was weighed, macerated with sterile mortar and pestle and emulsified with equal volume of sterile distilled water, centrifuged at $5000 \mathrm{rpm}$ for 10 minutes and the supernatant decanted as the extract, and used for analysis.

\subsection{Antibiotic Residues Detection}

The antibiotic residues were detected using Premi ${ }^{\circledR}$ Test kit. The Premi ${ }^{\circledR}$ Test is a commercially available agar diffusion based on principle of inhibition of microorganism like other microbiological tests. It comes with ampoules of agar imbedded with standardized number of spores of Bacillus stearothermophilus as test organism and Bromocrescol purple colour indicator. $100 \mu \mathrm{l}$ of each sample was inoculated into respective ampoules, along with a negative control ampoule inoculated with $100 \mu \mathrm{l}$ of distilled water. The incubator was pre-heated for 10 minutes and the ampoules incubated at $64^{\circ} \mathrm{C}$ for $3-4$ hours until the negative control turned yellow.

\section{RESULTS}

Those ampoules that remained purple after incubation were recorded as positive for antimicrobial residues, those that turned yellow were negative and those that were bluish to yellow were recorded as undecided for antibiotic residues.

\subsection{Antibiotic Residues Detected in Commercial Broilers}

Out of the 70 birds sampled, $42(60 \%)$ were positive while $28(40 \%)$ were negative for antibiotic residues as shown in Figure 1.

\subsection{Antibiotic Residues Detection in Sampled Markets}

Figure 2 is showing the market distribution of detected antimicrobial residues where of the three markets sampled, 19 (63.3\%) of the sampled birds from artisan were positive, 9 (45\%) of the birds from Gariki and 14 (70\%) of the birds sampled from main market were positive for antibiotic residues. No association $(\mathrm{P}<0.05)$ was found between antibiotic residues occurrence and the sampled markets at $P$ value of 0.241 when subjected to Chi-square analysis using GraphPad Prism 5.

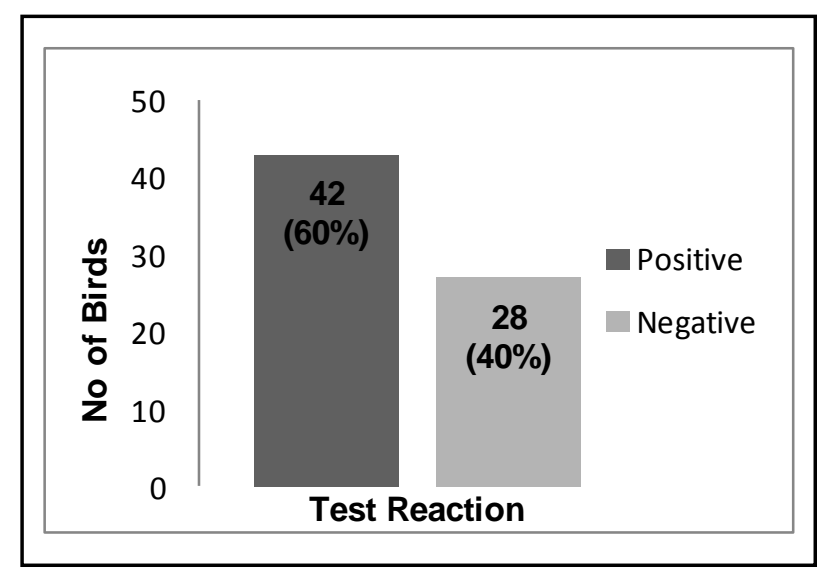

Figure 1. Antimicrobial residues in commercial poultry.

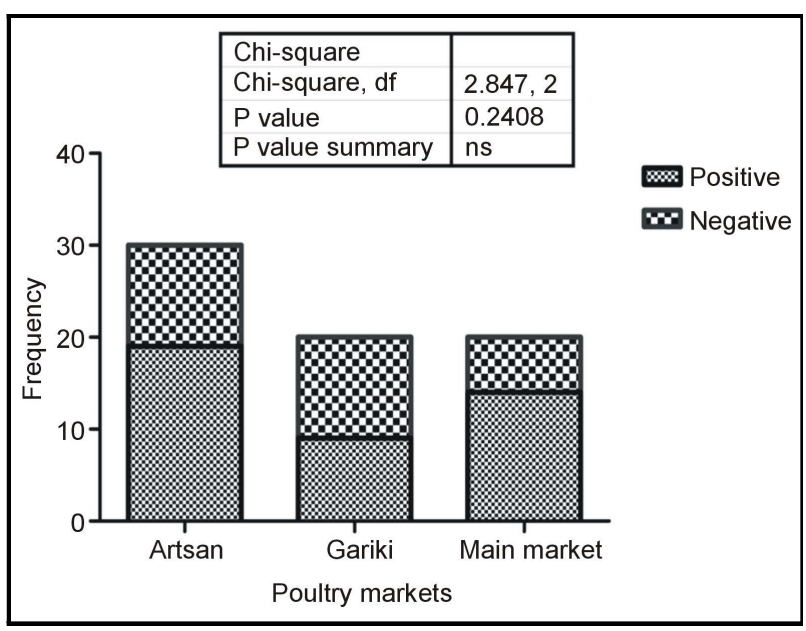

Figure 2. Market distribution of antimicrobial residues. 


\subsection{Antibiotic Residues Detection in Sampled Organs}

From a total of 280 organ samples tested for residues, 75 (26.8\%) were positive, 15 (5.4\%) were undecided (doubtful) while the remaining 190 were negative for antibiotic residues. In Figure 3, out of the 70 samples for each organ, $14.3 \%$ were positive and $10 \%$ doubtful for muscle samples; $48.6 \%$ were positive for kidney samples; liver samples had $22.9 \%$ positive and $2.9 \%$ doubtful and the Gizzard had $21.4 \%$ and $8.7 \%$ for positive and doubtful for antibiotic residues while the rest were negative. A strong association $(\mathrm{P}<0.05)$ was found between occurrence of antibiotic residues and the organ type with a $\mathrm{P}$ value of $<0.0001$ when subjected to Chi-square analysis using GraphPad Prism 5.

\section{DISCUSSION}

In the Premi ${ }^{\circledR}$ Test interpretation, the negative (yellow colouration) is due to the growth of the spores at $64^{\circ} \mathrm{C}$ that initiates an acidification process which causes the turning of a pH indicator from purple to yellow. The presence of antibiotic substances on the other hand will cause delay or inhibition of the spores, depending on the concentration of the residues, In the presence of residues therefore, the spores will not multiply and the $\mathrm{pH}$ indicator will remain purple. However, some samples were undecided between yellow and purple gearing towards light blue coloration. This may be associated with low concentrations of residues in those samples showing incomplete acidification of the medium due to partial inhibition. The $60 \%$ prevalence of antibiotic residues in commercial birds in this study is a clear indication that consumers may be exposed to violative levels of antimicrobial residues and this is consequent upon abuse and misuse of antimicrobials and most importantly, non-ob-

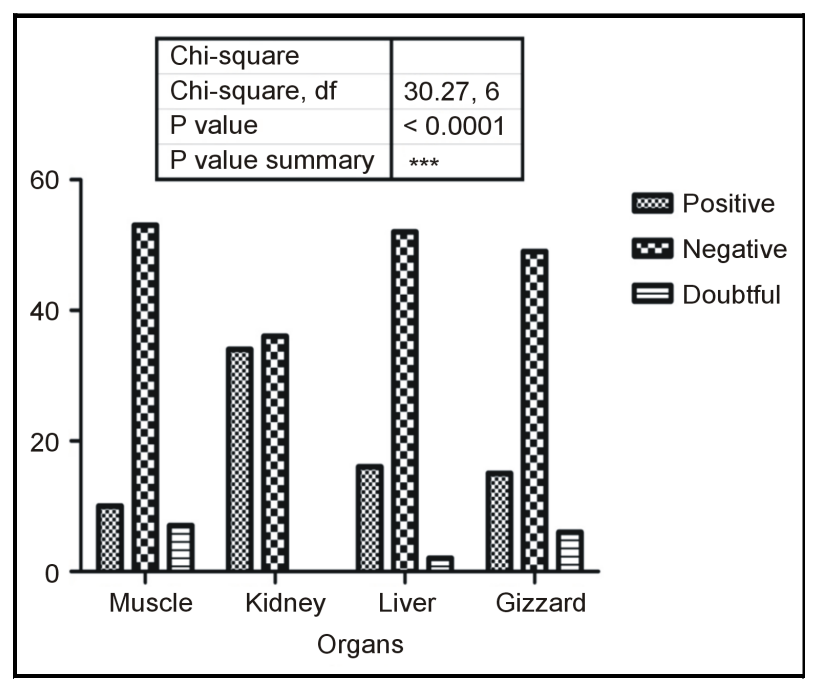

Figure 3. Organ distribution of antimicrobial residues. servance of withdrawal period. The non-prudent use of antibiotics was observed in Tanzania, by [10] in a cross sectional survey study they did on use and occurrence of drug residues in poultry farms in Morogoro where 70\% of the farms were positive for antimicrobial residues. Although Premi Test is not a quantitative method, it detects most antibiotics at or above their Maximum Residues Limits (MRL) or Tolerance Level as set by World Health Organisation (WHO) and can detect antibiotic residues in different poultry organ matrices as shown in the study. However, the test organism, Bacillus stearothermophilus is relatively not sensitive to quinolone antibiotics, hence there may be some false negative samples. Therefore, to cover the whole antibiotic spectrum, additional testing will be required [9]. Birds sampled from Main market have the highest proportion (70\%) of antimicrobial residues, $\mathrm{P}$ value of 0.241 which is greater than 0.05 probability shows that there is no association between occurrence of antimicrobial residues and the poultry market. The simple reason being that although, the three major poultry markets in Enugu urban, are located at and serve various zones, the commercial bird dealers can purchase birds from any zone irrespective of where the market is located. This is unlike the organ distribution of antibiotic residues where there is a significant $(\mathrm{P}<0.05)$ association between occurrence of antibiotic residues and the type of organ as indicated by the low $\mathrm{P}$ value of $<0.0001$. The kidney has the highest proportion of antibiotic residues and apart from it being the major excretory organ of most drugs, the Premi ${ }^{\circledR}$ test organism, Bacillus stearothermophilus is sensitive to the inhibitory activity of the lysozymes present in the kidney [11]. This is in line with a similar study done in Abuja, Northern Nigeria on antimicrobial residues in slaughter cattle where the kidney (89\%) had the highest occurrence of antimicrobial residues using the same test kit [12]. Although Premi ${ }^{\circledR}$ Test is a screening test and is basically quantitative; it will reduce the number of samples needed to be quantified by a more sensitive confirmatory test. It is however recommended for screening for antimicrobial residues since it can detect the many classes of antimicrobials in food animals and products in a single test.

\section{CONCLUSION}

The Premi ${ }^{\circledR}$ Test detection of antimicrobial residues in commercial poultry in this study indicates that the poultry consumers in the study area may be at risk of taking violative level of antimicrobial residues since the test detects residues at or above the WHO recommended Maximum residues Limits. Careful attention should then be given to irrational use of antimicrobials in animal production, to avoid problem of reduction in their potency and effectiveness since they are the vital drugs used in treating human infections. 


\section{ACKNOWLEDGEMENTS}

We would like to appreciate the efforts of Dr. Emmanuel Nna and the entire staff of Safety Molecular Pathology Laboratory (SMPL), University of Nigeria, Enugu Campus, for their immense help and hospitality during the period of this study. My appreciation also goes to Prof. Den-Chris Onah for close-marking the progress of the work and proof reading this article.

\section{REFERENCES}

[1] Dipeolu, M.A. and Alonge, D.O. (2002) Residues of streptomycin antibiotic in meat sold for human consumption in some States of SW Nigeria. Archivos de Zootecnia 51, 477-480.

[2] Kempe, M. and Verachtert, B. (2000) Cartridges with molecularly imprinted recognition elements for antibiotic residues monitoring in milk cream. Pure and Applied Biochemistry, Lunds Universitét Centre for Chemistry and Chemical Engineering Getingevagen, Lund, 1-10.

[3] Nisha, A.R. (2008) Antibiotic residues-A global health hazard. Veterinary World, 1, 375-377. http://dx.doi.org/10.5455/vetworld.2008.375-377

[4] Vollard, E.J., \& Clasener, H.A.L. (1994) Colonization resistance. Antimicrobial Agent Chemotherapy, 38, 409414. http://dx.doi.org/10.1128/AAC.38.3.409.

[5] Jones, G.M. (1999) On farm test for drug residues in milk-Virginia cooperative extension-Knowledge for the common wealth. Virginia Polytechnic and State University, Blacksburg.
[6] Cunha, B.A. (2001). Antibiotics side effects. Medical Clinics of North America, 85, 149-185.

[7] Kirbiš, A. (2006) Microbilogical 5-plate screening method for detection of tetracyclines, aminoglycosides, cephalosporines and macrolides in milk. Slovenian Veterinary Research, 43, 161-168.

[8] Pikkemaat, M.G. (2009) Microbial screening methods for detection of antibiotic residues in slaughter animals. Analytical Bioanalytical Chemistry, 395, 893-905. http://dx.doi.org/10.1007/s00216-009-2841-6

[9] Stead, S., Sharman, M., Tarbin, J.A., Gibson, E., Richmond, S. and Stark, J. (2004) Meeting maximum residue limits: An improved screening technique for the rapid detection of antimicrobial residues in animal food products. Food additives \& Contaminants, 21, 216-221 http://dx.doi.org/10.1080/02652030310001647280

[10] Nonga H.E., Mariki M., Karimuribo E.D. and Mdegela R.H. (2009) Assessment of antimicrobial usage and antimicrobial residues in broiler chickens in morogoro municipality, Tanzania. Pakistan Journal of Nutrition, 8, 203207. http://dx.doi.org/10.3923/pjn.2009.203.207

[11] Kirbis, A. (2007) Microbiological screening method for detection of aminoglycosides, $\beta$-lactams, macrolides, teteracyclines and quinolones in meat samples. Slovenian Veterinary Research, 44, 11-18.

[12] Omeiza, G.K., Ajayi, I.E. and Ode, J.O. (2012) Assessment of antimicrobial drug residues in beef in Abuja, the Federal Capital Territory. Nigeria. Veterinaria Italania, 48, 283-289. 